rely; nor can we rely on these until we can make them so demonstrable that everyone can ensure their repetition.

In simple terms, it is necessary to take the influence of the mind of the subject out of every observation that is made in relation to the action of a remedy upon him before the physiological influence can possibly be deduced.

$I$ have placed pain as an index from which a subjective part of evidence might sometimes be drawn. I think it necessary, however, to guard myself even on this point. There is such a wide distinction in respect to the pain felt by different persons, and such a difference in the same person at different times in regard to bearing pain, that it is most difficult to define even pain as a symptom in respect of degree. In the performance of local anæsthesia, in which I have had much practice, I often find that a difference of success may be ensured or not ensured, in almost any case, according to the circumstance, whether or not the person being operated upon can or cannot see the operative procedure. All small operations performed out of the sight of the patient, and which are so out of sight that he cannot see them if he would, are easily carried on under local anxsthesia; while other operations really less painful can hardly be permitted under the same process. Upon this fact depends so much of the discrepancy of opinion in relation to the local anxsthetic process. I removed once a tumour from a nervous lady, but in order that her attention might be kept apart from the operation, I encouraged her to keep her eyes fixed solely on a rosary which she held, and to let her mind continue in close attention to her devotions. In perfect silence that operation, which was tedious enough, was carried out without a single expression of pain on the part of the patient and with the statement afterwards that she had felt nothing whatever except at first an extreme cold. I did a smaller operation of a similar kind on another lady whom I could not keep at rest, and although the insensibility produced was deeper, and the operation much more quickly performed, she was calling out with pain all the time, and declared afterwards she felt at every step of the operation. In another case I produced local anæesthesia while the late Sir William Fergusson removed a small loose tumour from the ball of the thumb of a clergyman. This patient gave evidence, as it seemed to us, of the acutest suffering, and positively fainted while the sutures were being inserted, towards the close of the operation; but when he had recovered from his faintness, and I expressed my sorrow that he had felt the operation so acutely, he affirmed, and has ever since continued to affirm, that he never felt the slightest pain, and that his calling out and faintness were simply and solely the effects of scare or fear.

It is, then, only when we exclude the subjective causes of error, and are ready to receive objective evidence as the basis of sound research, that we can progress at all. Having taken this decisive step, we can first look around and see what agents we have at our command whereby we can systematically and apart from the will of the subject interfere with the physiological states of his body in a definite manner; and, secondly, we can ask whether by such interference we may do any good; whether our interference is scientifically warrantable for effecting what would not be effected if nothing were done.

The terms employed by the ancients lead us to discover that they had, in a rude way, correct notions as to the action of remedies by physiological interference. They classified their remedies on fair physiological grounds. They believed themselves to be in the possession of a series of remedies, which caused free secretions from the glands of the body-aperients, diuretics, emmenagogues, expectorants, diaphoretics, cholagogues. They believed themselves possessed of remedies which quickened or which depressed the circulation--stimulants and sedatives. They believed themselves possessed of agents that overcome muscular tonicityantispasmodics. They believed themselves possessed of agents which repress secretion-astringents. They believed themselves possessed of agents that relieve pain-hypnotics; and which produce sleep-narcotics. They believed themselves possessed of agents which reduce fever-febrifuges; and after the days of Stahl, antiphlogistics. They believed they held in their hands remedies that would soften hardened structures-emollients. They had the most con firmed belief that they possessed agents which, over and above food and drink, supplied power or force-tonics. Physiologically there is not a great deal to revise in the enumeration of these powerful agencies. The ancients with. out any doubt had them all, except perhaps the last, and they knew how to use them so as to produce objective effects. The errors they fell into consisted, $(a)$ in using their remedies too freely; $(b)$ in using them as if they were always called for; (c) in using them without inquiring whether the natural functions would not return without them; $(d)$ in using them sometimes at random, without inquiring what precisely was the natural function that was out of gear, and that, as a consequence, required to be directed back to its normal duty.

Objectivism pushed to an extreme was the error of old. As a basis it was correct; as a practice it was made too exclusive. It was through this error that that pure system of subjectivism called homœopathy found support. That system did its "proving" on the delusive method of inquiring after effects through the expression of the subject. What he felt was put down as the action of the agent. The imagining was the physiology, and as that allowed the disease for which the negative agent was administered to take its course with. out harm, the recovery in all cases, when recovery took place, was traced to the negative as if it were an affirmative fact. The disease did not get well-it was " cured." The idea of curing was, in fact, a fatal error in both the objective and subjective methods of treatment. In both it continues, but in the subjective far more now than in the objective school. In the subjective school the idealised dogma is a superstition, admirable for the propagandist. In the objective school dogma is giving way so hastily to doubt that the danger is of too great yielding of what are often positive lines of treatment, perfectly reliable, and admitting of being formularised into a series which all practitioners may safely and faithfully follow.

(To be continued.)

\section{BORACIC ACID IN THE TREATMENT OF CHOLERA.}

To the Editor of THE LANCET.

SIR,-Will you allow me to draw the notice of the profession to the value of boracic acid in the treatment of cholera? It is with considerable diffidence that I venture to write on a subject such as the treatment of cholera (which has so often been discussed, and with such poor results as regards the various remedies which have hitherto been recommended), feeling, as I do, that any new remedies or specifics must of necessity be looked on with distrust and incredulity.

I will not attempt here to explain the theory on which the use of this drug is based, or the grounds on which I was led to resort to its use, but will simply state that having had considerable experience in the treatment of this fatal malady in the course of numerous and extensive epidemics in Burmah and Southern India, and having employed all the various treatments which have had any claim to success with very poor results (the most successful even only yielding a percentage of from 45 to 50 recoveries), I was induced to consider whether any more efficacious remedy could not be resorted to. About this period the properties of boracic acid had recently been made public, and I determined to try its effects. The pure acid not being readily procurable, the biborate of soda was at first employed, with marked benefit, the percentage of recoveries rising from 70 to 75 per cent. Subsequently the pure acid was employed in ten-grain doses every two hours, combined with sodæ bibor., or sodæ bicarb. under which treatment every case recovered.

It was my intention to collect a large number of cases with a view to supplying statistics, but my health rendered a precipitate return to Europe imperative. Having, however, heard of the treatment being employed, as introduced by myself, by a professional friend to whom I had communicated it, in a recent epidemic with very favourable results, every case in which he resorted to it having recovered, I now venture to bring the treatment under notice, in the hope that it may prove as successful in the hands of others as it has done in my own. I would add a few notes with regard to the effects of the internal administration of the drug in this disease, but fear to prolong this communication. I may, however, say that in no case were any signs of irlitation or ill effects observed; and that in all of them the renal secretion was re-established with much greater facility than under any other mode of treatment. - I remain, Sir, yours obediently, 